\title{
Application of Green Idea in Energy-saving Design of Building HVAC System
}

\author{
Ministry of Agriculture Planning and Design Institute, Beijing 100125
}

\section{Introduction}

With the development of China's modernization, people's living standards are getting higher and higher. Similarly, the modernization of the continuous advancement of the residents of the building requirements are not only the beginning of the comfort and safety, and gradually pay more attention to human and sustainable design. In order to meet the growing needs of people, in response to China's sustainable development strategy to protect the ecological balance, green building followed. Green building to energy-saving emission reduction based on not only to meet people's harsh living requirements, more importantly, can solve the shortage of energy resources to achieve sustainable development. Among them, HVAC energy-saving technology is the key to the process of building design, green energy-saving buildings is particularly important. First, the HVAC system is the closest to the residents is also the first contact with the residents of the link; Secondly, the building of intelligent and humane increasingly become the main needs of the market, occupy an increasing proportion. HVAC technology can not only cater to consumer psychology but also the practice of its green concept, so as to promote the green building construction and improve building quality.

At present, China's per capita energy consumption is much lower than the world average, non-renewable energy also will be less. But people's demand for energy is high, the market price of ener- gy also will be higher and higher. However, the development of renewable resources in China is limited, its utilization rate is still at a low level. So it is important to address the contradiction between high demand and low utilization. HVAC is the necessary equipment in construction, in order to seek comfort and safety, HVAC systems need to consume a lot of energy to maintain balance, which will lead to a lot of energy consumption, also greatly increased the cost of the living. In addition, the long-term energy consumption undermines the ecological environment of the balance and development is not conducive to China's sustainable development. It can be seen that green energy-saving technology in the HVAC design is indispensable, it can not only meet the architectural comfort while saving limited energy, reduce energy consumption, but also makes the building more intelligent and humane, more on the protect of the environment and achieve sustainable development.

\section{In the green concept of HVAC design status quo}

1.1 The limitations of social cognition

Green concept is a new concept in recent years, this concept is to protect the ecological environment for the purpose of architectural ideas, but not widely used by the community. The main reasons are the following two aspects:

(1) The green concept of custody and visibility is not enough, leading to people's understanding of the concept is not enough,

\begin{abstract}
With the sustainable development strategy of our country attracting more and more attention, green projects are also designed to all kinds of industries, including construction. In the case of housing construction, the HVAC system is, to some extent, the most energy-intensive projects in the construction process. In order to meet the country's sustainable development strategy to meet the practical requirements of sustainable development, the need to green energy-saving environmental protection technology applied to the HVAC system, and the continuous development and popularization, from the country through the success of energy saving and environmental protection technology to reduce the HVAC system of the energy consumption, which makes the building energy consumption to a minimum. HVAC works in the entire construction project have a pivotal role, so HVAC project green energy-saving design in the green building development indispensable. This paper explains the concept of green energy saving design of HVAC project and illustrates the key of green energy saving technology in HVAC design under construction industry. The paper analyzes the HVAC design of Guangzhou Library as an example.
\end{abstract}

Key words: HVAC design; green concept; energy saving technology

Published online: 15th July, 2017 
so there is no deep understanding of the implementation of the green concept of values;

(2) The traditional concept of thinking deep-rooted, multi-part construction enterprises are still over-seeking comfort, do not attach importance to the building's energy-saving design, so the entire construction industry on the green concept of acceptance is not enough to ignore the environmental protection issues. Therefore, the idea of green ideas is still in the initial stage, all the industry and the public on the green concept is not enough understanding and attention, many construction behavior is still uphold the traditional building hue and ignore the green concept, resulting in the application of green concept in a very passive situation. In addition, the relevant departments did not take measures to improve the green awareness, nor the construction industry against green building design rigorous review.

\subsection{Design level of the problem}

Today, China's HVAC design level still maintain the traditional design concepts and concepts, the comfort as a primary requirement, ignoring the HVAC design process problems, leading to the lack of design of the entire industry level. In the process of HVAC design, there is no unified green concept for people's reference, and no green on the concept of environmental protection requirements for the implementation of people, has maintained a traditional design, resulting in a lot of waste of resources and energy consumption. This increase in the cost of construction, on the other hand to the environment to bring a greater burden.

\subsection{Application of new technology}

The lack of knowledge of the green concept seriously hinders the application of green ideas in HVAC design. Green ideas and energy-saving technologies were initially emerging in foreign countries. In the initial stage of application, China's introduction of new technologies from abroad is not yet mature, so the design cost is higher than the general technology, the level of science and technology has not yet reached a certain standard. Many construction enterprises are still in accordance with the traditional HVAC technology to carry out the design specifications, completely ignore the green concept of new technologies. New technology nobody cares, which makes the building HVAC design level in place, leading to the development of the entire construction industry stagnant.

\subsection{The quality of the designer is not high}

HVAC design industry, the quality of different personnel in the construction business design tend to tend to hire low cost of HVAC design staff. These low-cost designers are often of high quality, lack of experience, design level in general, will not choose green ideas and energy-saving technology for HVAC design, and so the traditional design of repeated applications, new design suffered cold, waste of resources has not been improved. Not only that, low-quality designers may also be caused by cost problems cut corners of the behavior, more to reduce the quality of the design.

\section{HVAC design principles of green ideas}

\subsection{HVAC design flexibility}

The flexibility of HVAC design is mainly manifested in the air conditioning system has a lot of adjustable. Air conditioning adjustable system is based on the different season into the regulation, according to the four seasons of different climate adjustment, to achieve "a system of multi-purpose" effect. The main implementation of the air-conditioning system has two: VAV air-conditioning system and VRV inverter air conditioner system. These two air-conditioning system is highly operational, in the latter part of the operation of the lower cost of consumption, more resources, but also reduce the cost of personnel, pay more attention to the quality of personnel operations. The comparison is shown in Table 1.

\subsection{Economic and practical design of HVAC design}

Economic practicality has always been the main goal pursued by people, and most in line with people's daily needs. Take the library HVAC design as an example, in the design of the principle of practicality, including the price of energy, equipment, cost performance and life and other issues, and then a solid design of the degree of comfort, practical and other services, and strive to high reduce the economic losses of residents. Therefore, in the library HVAC design, in ensuring the equipment period, but also consider the economic benefits of equipment maintenance work. In addition, the design should be adjusted at any time according to changes in the dynamic environment, scientific and rational design and equipment for the update and maintenance to provide room for adjustment.

\begin{tabular}{c|c}
\hline VAV air conditioning system & VRV inverter air conditioner system \\
\hline Energy saving up to $78 \%$ & Flexible and easy to install \\
\hline Saving air conditioning equipment capacity & Flexibility to adjust capacity \\
\hline
\end{tabular}

Table 1 VAV air conditioning system and VRV inverter air conditioner system of their respective advantages 
2.3 Principles of environmental protection

For the building resources and energy consumption, HVAC system occupies a certain proportion. Therefore, to control the energy consumption of HVAC systems is the key to building sustainable development. Library HVAC system design is still high energy consumption of the situation, which requires designers to innovate, put forward new programs, the use of new technologies to reduce the energy consumption of HVAC design. Of course, the process of achieving sustainable development is difficult, but also under the protection of the law and the system continue to work, and to propose and improve the new laws and systems.

\section{Application of Green Energy Saving Technology in HVAC De- sign}

\section{1 heat recovery technology}

Exhaust waste heat recovery technology and condensing heat technology is currently used in China often use two kinds of thermal recovery technology. The principle of waste heat is the heat exchange device through the heat recovery of the exhaust and the air into the heat exchange.

\subsection{Application of frequency conver- sion technology}

Frequency conversion technology is an early adoption of a green energy-saving technology. Frequency conversion technology can not only save energy, improve resource utilization, but also to protect the environment and maintain ecological balance. Therefore, the frequency conversion technology is one of the main roads to the development of HVAC design. Frequency conversion technology is for the construction of the indoor environment changes and continuous adjustment, environmental changes in two ways:

(1) Changes in the intensity of sunlight. The stronger the sun, the frequency of cold water regulation unit will increase the heat output;

(2) Changes in the number of indoor staff. Increased indoor staff, air conditioning adjustment fan will automatically increase the energy output.

Through the use of frequency conversion technology, can reduce the energy consumption of $35 \%$ to $40 \%$, saving the use of energy. The specific advantages of frequency conversion technology mainly in:

(1) Energy consumption equipment through the external temperature in time to adjust the frequency, fully energy conservation at the same time to meet people's needs.

(2) Various energy-consuming equipment can be individually controlled, do not affect each other, it will not interfere with the normal work of other equipment.

\subsection{Application of hydraulic balance} device

Hydraulic balance settings as the name implies, to ensure the hydraulic balance of the air conditioning system. In the artificial cannot achieve the hydraulic balance can also be through the hydraulic balance valve to strengthen control. Hydraulic balance valve has a dynamic hydraulic balance valve and static hydraulic balance valve two, the two kinds of balance valve application aspects are also different. Such as building HVAC system in the water fluctuations in the value of large, which can be used dynamic hydraulic balance valve, the other is generally the use of static hydraulic balance valve.

\subsection{Application of waste heat cycle technology}

Waste heat cycling technology is one of the earliest technologies and is now very common. Its working principle is to separate the heat through multiple circuits, in the run to produce waste heat and leave it for re-use. Waste heat cycle technology can serve the air conditioning system, promote the heating device, and improve the utilization of heat.

\subsection{Monitoring the environment}

Through the environmental testing technology to automatically detect and adjust the room temperature, including air humidity and air tem- perature to ensure the comfort of living.

\section{Conclusion}

With the increasing number of urban buildings, architectural design requirements are also rising. Building HVAC design is an important part of architectural design. Vigorously advocate the green concept, promote the development of energy-saving technology is to achieve sustainable demand, but in practice, there are still a series of problems, which requires continuous efforts to improve the HVAC design system to achieve sustainable development of the environment.

\section{References}

[1] Ran Li Mei, Hou Jingxin. Green Energy-Saving Technology in HVAC System Applications [J]. Automation and Instrumentation .2016 (12)

[2] Ma Ruoyuan. Analysis of Building HVAC Design Problems and Coping Strategies [J]. Doors and windows .2017 (02)

[3] Yan Long. HVAC Energy Saving And Heating of the Common Problems and Design Measures [J]. Intelligent City .2016 (03)

[4] Wang Na. Analysis of Green Building HVAC Energy-Saving Technology Design [J]. Sichuan Cement .2016 (08)

[5] XIE Ming, GUO Xiao-luan. Application of Green Concept and Energy Saving Technology in HVAC Design [J]. Residential \& Real Estate .2016 (27)

[6] Gao Bei-chao. Green Building Design Evaluation and Decision-Making System Research [D]. Nanjing Forestry University .2015

[7] Wang Kunpeng. Architectural Design Application and Benefit Analysis Based on Green Building Concept [D]. Dalian University of Technology .2015

[8] Wang Yu. Domestic and Foreign Green Building Evaluation System Comparative Study [D]. Jilin University of Architecture .2015 
[9] Chen Shaoliang. HVAC Design of Green Energy-Saving Technology Application Analysis [J]. China's new technology and new products .2015 (12)

[10] Zhou Yong. Air-Conditioning System Energy Consumption Diagnosis and Fault Detection [J]. Automation and Instrumentation .2012 (4)

[11] Zhao Shujuan. HVAC Design of Green Energy-Saving Technology Application Analysis [J]. Science and Technology Innovation Guide .2015 (33)

[12] Jiang Hong. On the HVAC Design Problems and Energy-Saving Measures [J]. Technology wind .2016 (15)

[13] Zhang Lindong, Li Yongchao, Shi Yannan. Analysis of Energy Saving Design of HVAC in Industrial Build- ings [J] .Jiangdong Industrial Technology .2015 (09)

[14] Kang Yingqin. Building Environment and Equipment Engineering (HVAC) Energy-Saving Design Analysis [J]. Technology Outlook .2015 (20)

[15] Xu Hui Ge. Residential Building HVAC Energy-Saving Design Points Analysis [J]. Enterprise Herald .2015 (19)

[16] Ahmad Jrade, Farzad Jalaei. Integrating Building Information Modeling With Sustainability to Design Building Projects at the Conceptual Stage [J]. Building Simulation. 2013 (4)

[17] Mohamed Hamdy, Ala Hasan, Kai Siren. A Multi-Stage Optimization Method for Cost-Optimal and Nearly-Zero-Energy Building Solutions in
Line with the EPBD-Recast 2010 [J].

Energy \& Buildings. 2013 